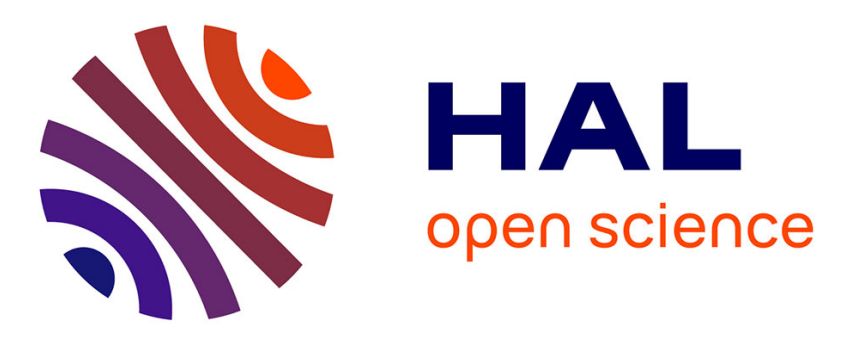

\title{
A nano quiescent current power management for autonomous Wireless sensor network
}

Fabien Todeschini, Christophe Planat, Patrizia Milazzo, Salvatore Tricomi, Pascal Urard, Philippe Benabes

\section{- To cite this version:}

Fabien Todeschini, Christophe Planat, Patrizia Milazzo, Salvatore Tricomi, Pascal Urard, et al.. A nano quiescent current power management for autonomous Wireless sensor network. 2013 IEEE 20th International Conference on Electronics, Circuits, and Systems (ICECS 2013), Dec 2013, Abu Dhabi, United Arab Emirates. 10.1109/ICECS.2013.6815539 . hal-00952300

\section{HAL Id: hal-00952300 \\ https://hal-centralesupelec.archives-ouvertes.fr/hal-00952300}

Submitted on 22 Sep 2014

HAL is a multi-disciplinary open access archive for the deposit and dissemination of scientific research documents, whether they are published or not. The documents may come from teaching and research institutions in France or abroad, or from public or private research centers.
L'archive ouverte pluridisciplinaire HAL, est destinée au dépôt et à la diffusion de documents scientifiques de niveau recherche, publiés ou non, émanant des établissements d'enseignement et de recherche français ou étrangers, des laboratoires publics ou privés. 


\title{
A NANO QUIESCENT CURRENT POWER MANAGEMENT FOR AUTONOMOUS WIRELESS SENSOR NETWORK
}

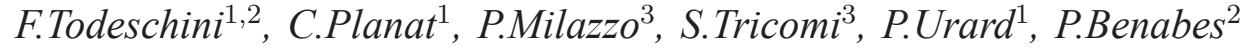 \\ ${ }^{1}$ STMicroelectronics, Crolles, FRANCE \\ ${ }^{2}$ Supelec, Gif-sur-Yvette, FRANCE \\ ${ }^{3}$ STEricsson, Catania, ITALY \\ Email: fabien.todeschini@st.com, christophe.planat@st.com, pascal.urard@st.com \\ patrizia.milazzo@stericsson.com, salvatore.tricomi@stericsson.com \\ philippe.benabes@supelec.fr
}

\begin{abstract}
A Nano quiescent current Power Management for Autonomous Wireless Sensor Network dedicated to indoor and outdoor Photovoltaic (PV) Energy Harvesting is presented. The standby current consumption is 130nA @ 2.4V. The battery can be charged with less than $5 \%$ of the harvested energy from low light (70 lux) to high light (1 sun). The IP starts charging at light level as low as 10 lux providing $\simeq 1 \mu W$. The voltage range is $2.4 \mathrm{~V}-3.2 \mathrm{~V}$. The system load can be powered up to $400 \mathrm{~mA}$. This power management is manufactured using the CMOS $90 \mathrm{~nm}$ technology in a $0.4 \mathrm{~mm}^{2}$ die area.
\end{abstract}

Index Terms - power management, wireless sensor network, energy harvesting, ultra-low power consumption.

\section{INTRODUCTION}

Autonomous Wireless Sensor Network (AWSN) products are becoming possible thanks to the progress of ultralow power techniques in microelectronics leading to energy consumption reduction. One of the goal of AWSN is to avoid the use of disposable batteries, making it more eco-friendly. Another goal is to extend the system life time. In an AWSN node, the system load is composed of a micro-controller, one or several radios, and one or several sensors. Most of the time, this system consumes a greater current than the harvested one [1]. So, the system has to be duty cycled and a rechargeable battery (or alternatively a supercap) has to be used as an energy tank. Thus, the battery is recharged by the harvester when the system is sleeping. The AWSN is viable when the energy levels are balanced between the quantity of harvested energy (including when the system is sleeping) and the energy consumed by the system (in active mode but also leakage and eventual counters inactive periods).

When the harvested energy is in the range of a few microwatts, the power management is not allowed to spend a large part of this energy. In this case, the use of hungry power converters is prohibited.

In [2] a switched capacitor converter is used to convert the harvested energy to the load. This architecture can be fully integrated but no more than $50 \%$ of the input energy can be converted. In [3] a converter is needed to boost up the input voltage of the PV cell to charge the battery. These kinds of architectures are required when the harvester is working in a different voltage range than the battery. In [4] the circuit consumption is very low and the power management is used to power or standby the system from the battery when required. But this device is working only from battery to the system and doesn't manage or protect the battery. In [5], an inductor based converter is used to convert photovoltaic energy harvested from indoor. The best end to end efficiency is $70 \%$ while consuming $0.8 \mu \mathrm{A}$ of static current. In [6], the charger uses a boost converter to charge a $4.2 \mathrm{~V}$ battery but also requires a low-dropout regulator to power the system load if working at $3 \mathrm{~V}$. The use of 2 converters to power a load decreases the global efficiency. In [7] the power management is composed of an inductor based boost converter (DC/DC). With this converter, the input voltage cannot be equal or higher than the system voltage. This DC/DC powers directly the system and a battery or super-capacitor is used as an energy buffer. The buffer is protected against over and under voltage, but it's not protected against overcharging current. Some kinds of battery can be damaged with a high harvested current [8]. With this application, the voltage of the harvester should always be under the battery voltage. The reported power management quiescent current is at 330nA. A coil and other external components are required for system configuration.

In our proposal, the consumption of the power management is below $5 \%$ of the harvested current thanks to different working modes. These modes are autonomously managed. The three parts (the harvester, the battery and the system load) are wisely chosen to work in the same voltage range. 
In this way, the efficiency can reach $87 \%$. A Lithium-Ion battery charger, essential to protect the battery against high charging current, is also implemented.

This paper is presented in 5 sections: the circuit architecture will be presented in section II, the efficiency calculations are described in section III, the experimental results in section IV and the conclusion in section V.

\section{POWER MANAGEMENT ARCHITECTURE}

The power management (PM) has been designed to work with commercial batteries and PV. These parts are entirely part of the system. The photovoltaic cells are working from low light up to high light and are well suitable to work for indoor applications. We consider we will get a better efficiency without a hungry Maximum Power Point Tracking (MPPT) system.

Fig. 1 shows the block schematic of the power management. It can be supplied either by a $5 \mathrm{~V}$ external power (i.e. USB) or by any source of power, in the range $0-6 \mathrm{~V}$. Depending on the light condition and the system current requirement, the PV can power the system and/or recharge the battery. This PM, supports batteries working in the range 2-3.2V. It embeds protection against over-voltage to avoid Li-Ion batteries over-charging. For this purpose, we use a Low Drop-Out (LDO) regulator that regulates the voltage at $3.2 \mathrm{~V}$. The under-voltage battery protection, designed to avoid the battery to be undercharged and be damaged, is designed with an hysteresis comparator that always senses the voltage of the battery. It will turns off the Power Switch (PS) when the battery is discharged to $2.4 \mathrm{~V}$. This will avoid the battery to be deeply discharge under $10 \%$ and then increase the battery life time (Lithium-Ion battery requirements). The comparator will turn PS when it is recharged to $2.8 \mathrm{~V}$.

We define different working modes to adapt to the light conditions and provide the best efficiency for the minimal power cost. The dark mode is the lowest power consumption mode. When no light is present, the system is powered only by the battery. The $\mathrm{S} 2$ switch, commanded by a resistor ladder that senses the PV voltage, is open to avoid leakage from battery through the PV_LDO. The current flows from the battery through the Fast Switch (FS) that is switched on and through the switch PS. (S3 is consequently open). Only the battery protection and some very low power digital circuitry consume a part of the battery energy. The total consumption of the PM is $130 \mathrm{nA}$ at $2.4 \mathrm{~V}$.

The second mode is the low-light mode: from a few tens of lux to around $3 \mathrm{klux}$. A voltage is present at the input of the PV_LDO, the output of the ladder is higher than the threshold of the switch, S2 is then turned-on. The PV_LDO is in follower mode, meaning that it is not regulating, the voltage drop is low $\left(V_{O U T} \simeq V_{I N}\right)$ and it provides all the energy harvested by the PV to the battery and/or the system. It also drives S3 (open) and FS (closed). This command occurs when the PV current capability is below the required

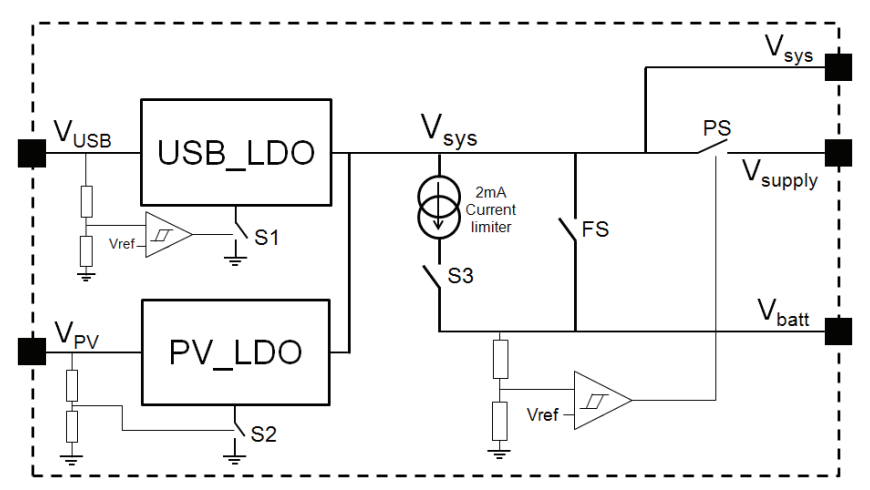

Fig. 1: Block schematic.

load current. The $2 \mathrm{~mA}$ current limiter is off, saving the power and the battery is recharged by FS. The battery can also power the system through the switch PS. In this mode, the PV_LDO consumes only $315 \mathrm{nA}$ at $150 \mathrm{lux}$ from the PV, which represent $1.75 \%$ of the harvested current. The total Power Management consumption is less than $580 \mathrm{nA}$ at $2.4 \mathrm{~V}$.

The third mode is the high-light mode. When the current from PV reaches a threshold fixed at $800 \mu \mathrm{A}$ the PV_LDO switches in regulator mode, consuming $5 \mu \mathrm{A}$, which represent $0.625 \%$ of the harvested current. The LDO regulates the internal common rail at $3.2 \mathrm{~V}$ avoiding the battery to be overcharged. It switches on S3 and off FS. The $2 \mathrm{~mA}$ limiter is active, consuming $\frac{I_{\text {charge }}}{1000}$. If the system requires a peak current higher than the PV can provide, FS switch is immediately closed in order to provide the required current. This is achieved by sensing $V_{\text {sys }}$ and the voltage of the battery. Once $V_{\text {sys }}<V_{\text {batt }}$ (which means high current is required), the FS is active. It will be open when the system goes back to sleep. $\left(V_{\text {sys }}>V_{\text {batt }}\right)$

The last mode is the full-power mode. This mode occurs only when an external power is connected to the USB pad. As soon as a voltage is applied on it, S1 is switched on by the comparator and the USB_LDO turns on and off the current limiter and the FS switch respectively and forces the PS switch whatever the battery voltage.

\section{EFFICIENCY CALCULATION}

The PV used for the design is working in the same voltage range than the battery. According to [9], the efficiency that we can have from a PV depending on the maximum power point and the effectively operating point is defined as:

$$
\begin{aligned}
\eta_{P V} & =\frac{P_{\text {transferred }}}{P_{M P P}} \\
P_{M P P} & =V_{M P P} \times I_{M P P}
\end{aligned}
$$

Depending on the current/voltage (IV) curves of the PV cell we are using, we can compute the power loss (or the efficiency) of the harvested power depending on the 
Maximum Power Point (MPP) and the Operating Point (OP), defined by $V_{\text {batt }}$.

The figure 2 presents a typical measured current/voltage (IV) and power/voltage (PV) curve and the position of the MPP and OP on the Power vs Voltage (PV) curve. The table I presents the efficiency of the transferred energy for different light conditions at different battery voltages:

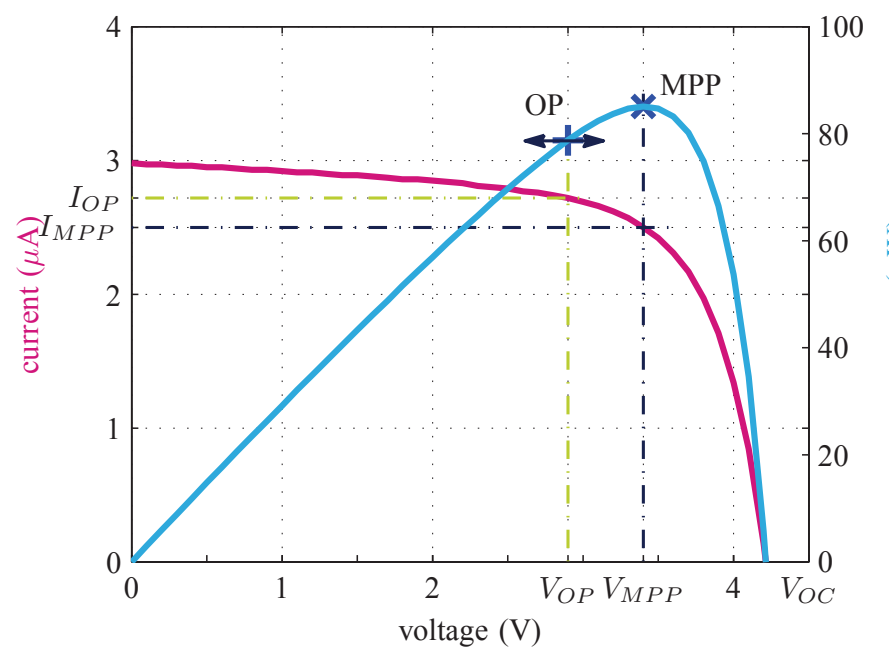

Fig. 2: IV and PV curve.

\begin{tabular}{|c|c|c|c|c|}
\hline$\underbrace{}_{\operatorname{lux}} V_{\text {batt }}$ & 2.4 & 2.6 & 2.8 & 3 \\
\hline 20 & $100 \%$ & $96 \%$ & $81.9 \%$ & $47 \%$ \\
\hline 200 & $90 \%$ & $94.8 \%$ & $97.6 \%$ & $100 \%$ \\
\hline 800 & $86 \%$ & $91.5 \%$ & $94.5 \%$ & $98.6 \%$ \\
\hline 2000 & $84 \%$ & $88.4 \%$ & $91 \%$ & $96 \%$ \\
\hline
\end{tabular}

Table I: Transferred energy on PV.

The efficiency of this kind of power management is the ability to transfer the power. If the input power in entirely transferred to the output, the efficiency will be $100 \%$. In other case, if there is a loss due to the joule effect, the efficiency will be:

$$
\eta_{P M}=\frac{P_{O U T}}{P_{I N}}
$$

The efficiency of the power management has been computed for different values in the table II:

\begin{tabular}{|c|c|c|c|c|}
\hline lux $V_{\text {batt }}$ & 2.4 & 2.6 & 2.8 & 3 \\
\hline 20 & $76.5 \%$ & $75.6 \%$ & $72.8 \%$ & $71.8 \%$ \\
200 & $85.6 \%$ & $85.4 \%$ & $85.6 \%$ & $86,4 \%$ \\
800 & $84,2 \%$ & $85 \%$ & $85.8 \%$ & $86.6 \%$ \\
2000 & $83 \%$ & $84.4 \%$ & $85.4 \%$ & $86.3 \%$ \\
\hline
\end{tabular}

Table II: PM efficiency.

The global efficiency is calculated as the efficiency of the power management by the efficiency of the OP vs MPP:

$$
\begin{aligned}
\eta & =\eta_{P V} \times \eta_{P M} \\
\eta & =\frac{P_{\text {transferred }} \times P_{\text {OUT }}}{P_{M P P} \times P_{I N}}
\end{aligned}
$$

With this equation, we can compute the global efficiency

\begin{tabular}{|c|c|c|c|c|}
\hline$V_{\operatorname{lux}} \quad V_{\text {batt }}$ & 2.4 & 2.6 & 2.8 & 3 \\
\hline 20 & $76.5 \%$ & $72.5 \%$ & $59.6 \%$ & $33.7 \%$ \\
\hline 200 & $77 \%$ & $81 \%$ & $83.5 \%$ & $86.4 \%$ \\
\hline 800 & $72.4 \%$ & $77.7 \%$ & $81 \%$ & $85.3 \%$ \\
\hline 2000 & $70 \%$ & $74.6 \%$ & $77.7 \%$ & $82.8 \%$ \\
\hline
\end{tabular}
from the previous tables. Different values are presented in the table III:

Table III: Global efficiency.

\section{EXPERIMENTAL RESULTS}

Simulations and chip measurements are matching and the power management has been tested in a global wireless sensor node. Table IV compares the power management

\begin{tabular}{|c|c|c|}
\hline light condition $I_{P M}$ & simulations & measurements \\
\hline & $156 n A$ & $130 n A$ \\
\hline low light & $572 n A$ & $500 n A$ \\
\hline high light & $5.3 \mu \mathrm{A}$ & $5.2 \mu \mathrm{A}$ \\
\hline
\end{tabular}
consumptions between the simulations and measures for the tree harvesting modes:

Table IV: Simulations vs Measurements.

The figure 3 shows the 3 modes of the power management: the dark mode, when the PV provides no current, the low-light mode where the current from PV goes directly through the battery and the high-light mode, the most power hungry mode, with regulation and current limiter for battery charging:

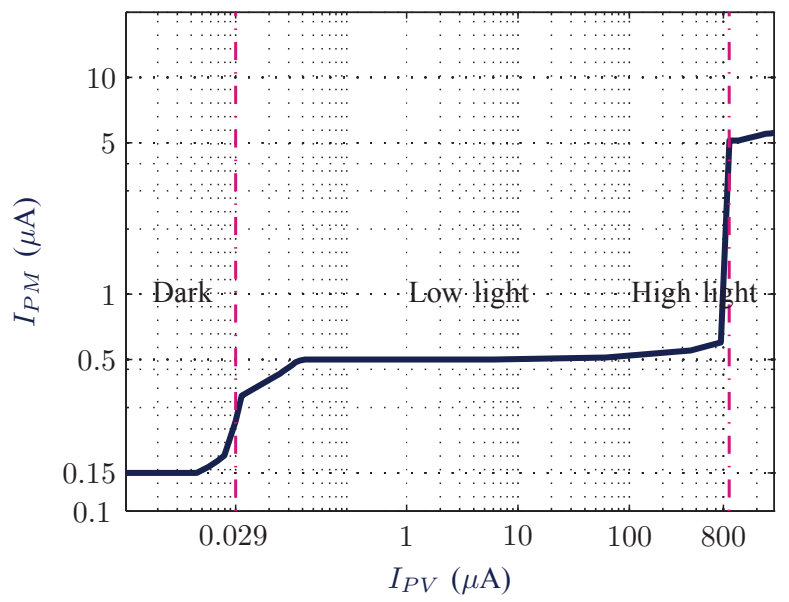

Fig. 3: PM consumption vs PV current. 
The table $\mathrm{V}$ presents the comparison of our solution versus the other published solutions :

\begin{tabular}{|c|c|c|c|c|}
\hline & {$[5]$} & {$[6]$} & {$[7]$} & This work \\
\hline quiescent current & $650 \mathrm{nA}$ & $625 \mathrm{nA}$ & $330 \mathrm{nA}$ & $130 \mathrm{nA}$ \\
\hline $\begin{array}{c}\text { overcharging } \\
\text { current protection }\end{array}$ & $\mathrm{NO}$ & $\mathrm{NO}$ & $\mathrm{NO}$ & YES \\
\hline $\begin{array}{c}\text { Power } \\
\text { throughput }\end{array}$ & $5 \mu \sim 10 \mathrm{~mW}$ & $1 \mu \sim 0.1 \mathrm{~W}$ & $10 \mu \sim 0.3 \mathrm{~W}$ & $1 \mu \sim 0.5 \mathrm{~W}$ \\
\hline $\begin{array}{c}\text { input charging } \\
\text { voltage }\end{array}$ & $0.5 \sim 2 \mathrm{~V}$ & $0.8 \sim 5.7 \mathrm{~V}$ & $0.13 \sim 3 \mathrm{~V}$ & $V_{\text {batt }} \sim 6 \mathrm{~V}$ \\
\hline process & $250 \mathrm{~nm}$ & $\mathrm{NA}$ & $\mathrm{NA}$ & $90 \mathrm{~nm}^{2}$ \\
\hline $11 \mathrm{~mm}^{2}$ & & $0.4 \mathrm{~mm}^{2}$ \\
\hline
\end{tabular}

Table V: Comparison of this work with recently published work.

The fig. 4 is the micrograph of the chip fabricated in $90 \mathrm{~nm}$ with an effective area of $0.4 \mathrm{~mm}^{2}$ :

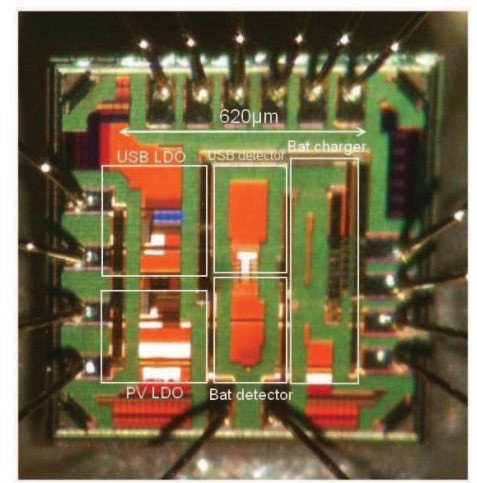

Fig. 4: Micrograph of the Power Management in CMOS 90nm.

\section{CONCLUSION}

In this paper, a power management system from photovoltaic harvester to battery and to system load is presented.

Typical commercial power management doesn't include battery protection for charging current. Most of rechargeable lithium batteries are suitable for wireless sensors but require careful attention for charging. Our solution propose an areaefficient complete system power management for very lowenergy harvesting. With a suitable battery and PV, this PM is convenient for AWSN. The measurements show very low power consumption with less than $130 \mathrm{nA}$ standby current in a tiny $0.4 \mathrm{~mm}^{2}$ die area. The efficiency is higher than $85 \%$ from $30 \mu \mathrm{A}$ of the harvested current (corresponding to 200 lux: table II).

\section{REFERENCES}

[1] Zhi Ang Eu, H. Tan, and W.K.-G. Seah, "Wireless sensor networks powered by ambient energy harvesting: An empirical characterization," in Communications (ICC), 2010 IEEE International Conference on, 2010, pp. 1-5.

[2] D. Maurath and Y. Manoli, "A self-adaptive switchedcapacitor voltage converter with dynamic input load control for energy harvesting," in ESSCIRC, 2009. Proceedings of, Sept., pp. 284-287.

[3] Hua Yu, Hanzhong Wu, and Yumei Wen, "An ultralow input voltage power management circuit for indoor micro-light energy harvesting system," in Sensors, 2010 IEEE, nov. 2010, pp. $261-264$.

[4] Zhangcai Huang and Y. Inoue, "A sub-100nA power management system for wireless structure health monitoring applications," in Circuits and Systems (ISCAS), 2011 IEEE International Symposium on, may 2011, pp. $2897-2900$.

[5] Yifeng Qiu, C. Van Liempd, B. Op het Veld, P.G. Blanken, and C. Van Hoof, " $5 \mu$ w-to- $10 \mathrm{mw}$ input power range inductive boost converter for indoor photovoltaic energy harvesting with integrated maximum power point tracking algorithm," in Solid-State Circuits Conference Digest of Technical Papers (ISSCC), 2011 IEEE International, 2011, pp. 118-120.

[6] Maxim Integrated Circuits, "Max17710 - energy harvesting charger and protector datasheet, 2011," http://datasheets.maximintegrated.com/en/ds/MAX17710.

[7] K. Kadirvel, Y. Ramadass, U. Lyles, J. Carpenter, V. Ivanov, V. McNeil, A. Chandrakasan, and B. LumShue-Chan, "A 330nA energy-harvesting charger with battery management for solar and thermoelectric energy harvesting," in Solid-State Circuits Conference Digest of Technical Papers (ISSCC), 2012 IEEE International, feb. 2012, pp. $106-108$.

[8] MAXELL, "Lithium manganese dioxide rechargeable battery," Tech. Rep., Hitachi Maxell, Ltd, http : //biz.maxell.com/files etc/6/catalog/en/ML_13e.pdf.

[9] R. Belu, "Design and analysis of a micro-solar power for wireless sensor networks," in Communications (COMM), 2012 9th International Conference on, june 2012, pp. $275-278$. 